\title{
Normalized expression for solutions to linear fuzzy differential equations under combination of differences
}

\author{
Yurilev Chalco-Cano ${ }^{1}$ Alireza Khastan ${ }^{2}$ Rosana Rodríguez-López ${ }^{3}$ \\ ${ }^{1}$ Instituto de Alta Investigación, Universidad de Tarapacá, Casilla 7D, Arica, Chile \\ ${ }^{2}$ Dpt. Mathematics, Institute for Advanced Studies in Basic Sciences (IASBS), Zanjan 45137-66731, Iran \\ ${ }^{3}$ Dpto. Análisis Matemático, Universidad de Santiago de Compostela, Santiago de Compostela, 15782, Spain
}

\begin{abstract}
We give a normalized expression for the solutions to the initial value problem for some linear fuzzyinterval differential equations by using a general notation which allows the combination of two types of differences. By switching between these types of differences, we derive several expressions for solutions corresponding to strongly generalized differentiability, providing a general formulation for these solutions to linear problems.
\end{abstract}

Keywords: Linear fuzzy differential equations, Strongly generalized differentiability, Operations with fuzzy intervals, Solutions

\section{Introduction}

The study of fuzzy differential equations has attracted the interest of many researchers thanks to the development of the concept of differentials of fuzzy functions $[2,3,5,11,15,16,31,38]$ and other useful techniques $[17,18,25,27,34,39]$, leading to continuous advances in the solvability of this type of equations since the publication of $[19,36,20]$.

The analysis of uncertain systems has been developed from different points of view which include the use of several concepts of differences and derivatives, such as the Hukuhara difference and derivative $[15,20]$, strongly generalized derivative $[2,3,4,8,21]$, generalized Hukuhara difference and differentiability $[5,11,37,38]$, but also from different approaches such as differential inclusions (starting in [17] and continuing, for instance, in $[10,18,35])$, the use of different representations of fuzzy numbers [39], the embedding of fuzzy sets on spaces with a linear structure [34], the detailed analysis of the implications of Zadeh's extension principle $[7,27,33]$, the use of generalized metric spaces [30] or the study of the connections between different approaches $[6,8,9]$ and the perspectives of the problem [1].

The study of the initial value problems for linear fuzzy differential equations has been accomplished by many authors by using the different types of derivatives $[12,13,14,21,22,24,29,36]$. In the literature, we can also find some results on periodic boundary value problems [32] or even functional fuzzy differential equations [23, 26]. Numerical approach has also been developed (see, for instance, [28]).

Here, we do not discuss the advantages of the different methods available to obtain the solution to a fuzzy differential equation. The approach of Zadeh's extension principle to get a fuzzy solution starting from a deterministic solution allows to obtain a reasonable solution to the problem of interest. This approach is not affected by the choice of a different formulation for the linear problem as long as the corresponding real equations are equivalent, in such a way that the existence of a unique solution for all the equivalent real differential equations allows to obtain a unique fuzzy solution by applying Zadeh's extension principle. However, if we use a fuzzy derivative to define the concept of solution, then several similar differential equations (which coincide in the real case) might not be equivalent and lead to solutions with very different properties.

It is considered (see [10]) that the approach following Zadeh's extension principle is adequate since it preserves some interesting properties of the classical solutions. Nevertheless, the computation using this point of view can be difficult under certain circumstances [10], so that other approaches are useful both as interesting methods by themselves and to get approximations of the problem.

Moreover, the analysis of fuzzy differential equations based on different concepts of fuzzy derivatives is also an interesting issue (see [4]), in addition to the achievements related to the treatment of the problem without the requirement of a fuzzy derivative concept. Therefore, this study is motivated by the interest arisen in the study of the properties of the solutions to fuzzy differential equations by using different types of derivatives, which are adapted to the special structure and particularities of fuzzy intervals, in such a way that the behavior of the solutions to fuzzy problems may differ substantially from the classical case.

The formulation used in this work is based on the use of strongly generalized differentiability, since the corresponding solutions show interesting behavior and properties which vary depending on the type of differentiability chosen, being adapted to diverse 
situations. As mentioned above, there are other approaches independent of the particularities of a fuzzy derivative such as Zadeh's extension principle and differential inclusions' approach, which are also interesting.

For the essential concepts on fuzzy sets and fuzzy differential equations, we refer, for instance, to $[15,25]$. Some additional notation needed for this contribution can be also found, for instance, in the references $[3,19]$.

\section{Preliminaries}

We consider here the space of fuzzy intervals $\mathbb{R}_{\mathcal{F}}$ (the set of mappings from $\mathbb{R}$ to $[0,1]$ which are normal, upper semi-continuous, fuzzy-convex and compact-supported). For $u \in \mathbb{R}_{\mathcal{F}}$ and $0<\alpha \leq 1$, we can define the $\alpha$-level set of $u$ by the expression

$$
[u]^{\alpha}=\{t \in \mathbb{R}: u(t) \geq \alpha\}
$$

and the set $[u]^{0}=\overline{\{t \in \mathbb{R} \mid u(t)>0\}}$ is called the support of $u$.

By the properties of fuzzy intervals, the $\alpha$-level set of $u \in \mathbb{R}_{\mathcal{F}}$ is a compact interval, for every $\alpha$. For the solvability of differential equations over the space of fuzzy intervals, it is very useful the notation $[u]^{\alpha}=\left[\underline{u}^{\alpha}, \bar{u}^{\alpha}\right], \alpha \in[0,1]$, for the level sets. Besides, in the space $\mathbb{R}_{\mathcal{F}}$, the operations of sum $u+v$ and multiplication by a real scalar $\lambda \cdot u$ are defined levelwise:

$$
[u+v]^{\alpha}=[u]^{\alpha}+[v]^{\alpha},[\lambda \cdot u]^{\alpha}=\lambda[u]^{\alpha}, \forall \alpha \in[0,1] .
$$

The space $\mathbb{R}_{\mathcal{F}}$ is a complete metric space [15] with the distance $D$ defined as

$$
D(u, v)=\sup _{\alpha \in[0,1]} \max \left\{\left|\underline{u}^{\alpha}-\underline{v}^{\alpha}\right|,\left|\bar{u}^{\alpha}-\bar{v}^{\alpha}\right|\right\},
$$

for $u, v \in \mathbb{R}_{\mathcal{F}}$. We use the concept of integration for fuzzy-valued functions as given in [3].

Concerning the different approaches in the solvability of fuzzy differential equations, we consider here strongly generalized differentiability and we use a simple notation which allows the combination of two types of differences, with the aim of finding a common framework to compare the different expressions known. As mentioned, other approaches are, for instance, those in $[4,8,27,29,30,38,39]$.

Definition 1 Given $u, v \in \mathbb{R}_{\mathcal{F}}$, if there exists $z \in$ $\mathbb{R}_{\mathcal{F}}$ such that $u=v+z$, then we say that $z$ is the $H$-difference of $u$ and $v$ (denoted $u \ominus v$ ).

Note that this concept of difference is not equivalent to the addition of the opposite element.

Next, we recall the concept of generalized differentiability as introduced in [3] (see also [4, 8, 23, 28]) for fuzzy functions defined on $I \subseteq \mathbb{R}$ an open interval.
Definition 2 ([3]) Let $F: I \rightarrow \mathbb{R}_{\mathcal{F}}$ and fix $t_{0} \in I$. We say that $F$ is differentiable at $t_{0}$ if there exists an element $F^{\prime}\left(t_{0}\right) \in \mathbb{R}_{\mathcal{F}}$ such that either:

(i) for all $h>0$ sufficiently close to 0 , the $H$ differences $F\left(t_{0}+h\right) \ominus F\left(t_{0}\right), F\left(t_{0}\right) \ominus F\left(t_{0}-h\right)$ exist and the limits (in the metric $D$ )

$$
\begin{aligned}
\lim _{h \rightarrow 0^{+}} & \frac{F\left(t_{0}+h\right) \ominus F\left(t_{0}\right)}{h} \\
& =\lim _{h \rightarrow 0^{+}} \frac{F\left(t_{0}\right) \ominus F\left(t_{0}-h\right)}{h}=F^{\prime}\left(t_{0}\right),
\end{aligned}
$$

or

(ii) for all $h>0$ sufficiently close to 0 , the $H$ differences $F\left(t_{0}\right) \ominus F\left(t_{0}+h\right), F\left(t_{0}-h\right) \ominus F\left(t_{0}\right)$ exist and the limits (in the metric $D$ )

$$
\begin{aligned}
\lim _{h \rightarrow 0^{+}} & \frac{F\left(t_{0}\right) \ominus F\left(t_{0}+h\right)}{-h} \\
& =\lim _{h \rightarrow 0^{+}} \frac{F\left(t_{0}-h\right) \ominus F\left(t_{0}\right)}{-h}=F^{\prime}\left(t_{0}\right) .
\end{aligned}
$$

In the references $[3,8]$, the fundamental properties of this derivative can be found.

Definition 3 Given $u$, $v$ two fuzzy intervals, by $u \widehat{\ominus} v$ we denote either the H-difference $u \ominus v$ (provided it exists) or the addition of the opposite element $u+(-1) v$.

In Definition 3, the notation $\widehat{\ominus}$ represents the possibility of choosing one of the two options, in the sense that both of them are possible in many cases. Depending on the particular choice, different situations may appear.

In this note, the use of this general notation $\widehat{\theta}$ allows to give a uniform expression for the solutions to some linear fuzzy differential equations depending on the particular meaning we give to $u \widehat{\ominus} v$. Of course, the interpretation of $u \widehat{\ominus} v$ as $u \ominus v$ is subject to its existence, which has to be checked appropriately but, here, we are mainly interested in the usefulness of this notation to give uniform expressions for the solutions to linear fuzzy differential equations.

\section{Solving fuzzy linear differential equations}

The initial value problem

$$
\left\{\begin{array}{l}
y^{\prime}(t)=a(t) y(t)+b(t), \quad t \in I \\
y(0)=y_{0}
\end{array}\right.
$$

was considered in [4], where $y_{0} \in \mathbb{R}_{\mathcal{F}}, a: I \rightarrow \mathbb{R}$ and $b: I \rightarrow \mathbb{R}_{\mathcal{F}}$ and this problem is not equivalent to any of the following:

$$
\left\{\begin{array}{l}
y^{\prime}(t)+(-a(t)) y(t)=b(t), \\
y(0)=y_{0}
\end{array}\right.
$$

or

$$
\left\{\begin{array}{l}
y^{\prime}(t)+(-b(t))=a(t) y(t), \\
y(0)=y_{0},
\end{array}\right.
$$


which are not equivalent either (see [4]). Moreover, if $y$ is simultaneously a solution to (1) and (2), then it is necessarily real. It is also well-known [4], that there exists no fuzzy (non-real) solution to problem

$$
\left\{\begin{array}{l}
y^{\prime}(t)+(-b(t))+(-a(t)) y(t)=\tilde{0} \\
y(0)=y_{0}
\end{array}\right.
$$

In this note, we provide a normalized expression for the solutions to problems (1)-(3) from the point of view of the use of the notation $\widehat{\ominus}$, which allows to formulate the strongly generalized differentiable solutions under a common style.

In what follows, the coefficients $a$ and $b$ in the above-mentioned problems are continuous functions in an open interval $I \subseteq \mathbb{R}\left(a: I \rightarrow \mathbb{R}, b: I \rightarrow \mathbb{R}_{\mathcal{F}}\right)$ and the initial condition $y_{0}$ is a fuzzy interval.

As a background for our study, the expressions of the solutions to some equations of types (1)-(3) are provided in [4]. Besides, in [22], the general expression of the solutions to (1) are studied in terms of the sign of the coefficient $a$. We include these expressions here for completeness.

In what follows, for simplicity, we also use the notation

$$
\varphi(t)=\int_{0}^{t} a(u) d u, \quad t \in I .
$$

Theorem 1 ([22]) For $a<0$, the (i)-solution to problem (1) is given by

$$
\begin{aligned}
y_{1}(t)= & \cosh (\varphi(t))\left(y_{0}+\int_{0}^{t} \psi(s) d s\right) \\
& +\sinh (\varphi(t))\left(y_{0}+\int_{0}^{t} \psi(s) d s\right),
\end{aligned}
$$

where

$$
\psi(s)=b(s) \cosh (\varphi(s)) \ominus b(s) \sinh (\varphi(s)),
$$

provided that the above H-differences exist.

On the other hand, for $a<0$, the (ii)-solution to problem (1) is given by

$$
y_{2}(t)=e^{\varphi(t)}\left(y_{0} \ominus \int_{0}^{t}(-b(s)) e^{-\varphi(s)} d s\right),
$$

provided that the H-differences exist.

Proof: See [4] for the expression of the (ii)-solution and [22] for the expression of the (i)-solution.

Theorem 2 ([22]) For $a>0$, the (i)-solution to problem (1) is given by

$$
y_{3}(t)=e^{\varphi(t)}\left(y_{0}+\int_{0}^{t} b(s) e^{-\varphi(s)} d s\right) .
$$

On the other hand, for $a>0$, the (ii)-solution to problem (1) is given by

$$
\begin{aligned}
y_{4}(t)= & \cosh (\varphi(t))\left(y_{0} \ominus \int_{0}^{t} \phi(s) d s\right) \\
& \ominus-\sinh (\varphi(t))\left(y_{0} \ominus \int_{0}^{t} \phi(s) d s\right),
\end{aligned}
$$

provided the previous H-differences exist, where

$$
\phi(s)=b(s) \sinh (\varphi(s))-b(s) \cosh (\varphi(s)) .
$$

Proof: The case of the (i)-solution can be seen in [4], while the (ii)-solution is considered in [22].

On the other hand, the solutions to problems (2) and (3) are provided in $[4,24]$.

Theorem 3 ([24]) Let $a<0$ and consider

$$
y_{5}(t)=e^{\varphi(t)}\left(y_{0}+\int_{0}^{t} b(s) e^{-\varphi(s)} d s\right)
$$

and

$$
\begin{aligned}
y_{6}(t)= & \cosh (\varphi(t))\left(y_{0} \ominus(-1) \int_{0}^{t} \psi(s) d s\right) \\
& +\sinh (\varphi(t))\left(y_{0} \ominus(-1) \int_{0}^{t} \psi(s) d s\right),
\end{aligned}
$$

where $\psi$ is defined in Theorem 1, provided that the $H$-differences in (6) and the expression of $\psi$ exist.

Then the following assertions are valid:

- $y_{5}$ is a (i)-solution to problem (2) on I (if it is (i)-differentiable on I).

- $y_{6}$ is a (ii)-solution to problem (2) on I (if it is (ii)-differentiable on I).

- $y_{5}$ is a (ii)-solution to problem (3) on I (if it is (ii)-differentiable on I).

- $y_{6}$ is a (i)-solution to problem (3) on I (if it is (i)-differentiable on I).

Theorem 4 ([24]) Let $a>0$ and consider

$$
\begin{aligned}
y_{7}(t)= & \cosh (\varphi(t))\left(y_{0}-\int_{0}^{t} \phi(s) d s\right) \\
& \ominus-\sinh (\varphi(t))\left(y_{0}-\int_{0}^{t} \phi(s) d s\right),
\end{aligned}
$$

provided that the levelwise $H$-differences define, for each $t \in I$, a fuzzy interval $y_{7}(t)$ ( $\phi$ is given in Theorem 2) and

$$
y_{8}(t)=e^{\varphi(t)}\left(y_{0} \ominus \int_{0}^{t}(-b(s)) e^{-\varphi(s)} d s\right),
$$

provided that the previous $H$-differences exist.

Then the following assertions are valid:

- $y_{7}$ is a (i)-solution to problem (2) on I (if it is (i)-differentiable on I).

- $y_{8}$ is a (ii)-solution to problem (2) on I (if it is (ii)-differentiable on I).

- $y_{7}$ is a (ii)-solution to problem (3) on I (if it is (ii)-differentiable on I).

- $y_{8}$ is a (i)-solution to problem (3) on I (if it is (i)-differentiable on I).

Remark 1 From the previous results, it is obvious that the expressions $y_{2}$ and $y_{8}$ are equal (provided they exist) and the same for $y_{3}$ and $y_{5}$. However, note that the use of their respective expressions strongly depends on the sign of a. 
Next, we give a uniform expression for the solutions obtained in Theorems 1-4, by the introduction of the general notation of the difference $\widehat{\theta}$. In the following, we represent with the symbol $(*)$ the cases where the choice $\widehat{\theta}=\ominus$ is used, so that additional restrictions have to be imposed in order to guarantee the existence of the corresponding $\mathrm{H}$ differences.

First, we provide the expression which generalizes $y_{2}$ (or $y_{8}$ ) and $y_{3}$ (or $y_{5}$ ) under a common frame.

Theorem 5 The function

$$
y(t)=e^{\varphi(t)}\left(y_{0} \widehat{\ominus}(-1) \int_{0}^{t} b(s) e^{-\varphi(s)} d s\right)
$$

represents, for $a<0$ :

- (ii)-solution to problem (1) (*);

- (i)-solution to problem (2), provided it is (i)differentiable;

- (ii)-solution to problem (3), provided it is (ii)differentiable

and, for $a>0$ :

- (i)-solution to problem (1);

- (ii)-solution to problem (2), if it is (ii)differentiable (*);

- (i)-solution to problem (3), if it is (i)differentiable (*).

Proof: Indeed, if we interpret $\widehat{\ominus}$ as $\ominus$ in (9), we obtain the functions $y_{2}$ and $y_{8}$. On the other hand, if $u \widehat{\ominus} v$ is understood as $u+(-1) v$ in $(9)$, then we obtain the functions $y_{3}$ and $y_{5}$. The conclusion follows from Theorems 1-4.

Concerning expressions $y_{1}, y_{4}, y_{6}$ and $y_{7}$, we consider the following function (provided it is welldefined):

$$
\begin{aligned}
y(t)= & \cosh (\varphi(t))\left(y_{0} \widehat{\ominus}(-1) \int_{0}^{t} \gamma(s) d s\right) \\
& \widehat{\ominus}-\sinh (\varphi(t))\left(y_{0} \widehat{\ominus}(-1) \int_{0}^{t} \gamma(s) d s\right),
\end{aligned}
$$

where

$$
\gamma(s)=b(s) \cosh (\varphi(s)) \widehat{\ominus} b(s) \sinh (\varphi(s)) .
$$

In order to represent that any of the $\widehat{\theta}$ differences can be chosen differently (if the corresponding function exists), we rewrite this expression by using the differences $\widehat{\ominus}_{1}, \widehat{\ominus}_{2}$ and $\widehat{\ominus}_{3}$, in such a way that the three of them represent $\widehat{\theta}$ but they can be interpreted in the same or different sense, by choosing one of the interpretations given in Definition 3. This way, we work with the function

$$
\begin{aligned}
y(t)= & \cosh (\varphi(t))\left(y_{0} \widehat{\ominus}_{1}(-1) \int_{0}^{t} \gamma(s) d s\right) \\
& \widehat{\ominus}_{2}-\sinh (\varphi(t))\left(y_{0} \widehat{\ominus}_{1}(-1) \int_{0}^{t} \gamma(s) d s\right)
\end{aligned}
$$

and

$$
\gamma(s)=b(s) \cosh (\varphi(s)) \widehat{\ominus}_{3} b(s) \sinh (\varphi(s)),
$$

where the differences can be switched, provided the resulting function is well-defined. Taking different combinations of the differences $\widehat{\ominus}_{1}, \widehat{\theta}_{2}$ and $\widehat{\ominus}_{3}$, we prove that we can derive the different types of solutions, so that (10)-(11) will represent a normalized expression for all the solutions given in Theorems 1 4. We stress the fact that (10) gives uniformity to the various expressions, more than paying attention to the conditions guaranteeing the good definition of the function itself.

To simplify the proof of the following result, we define $\ominus_{1}$ and $\ominus_{2}$, respectively, by $u \ominus_{1} v=u \ominus v$ and $u \ominus_{2} v=u+(-1) v$.

Theorem 6 The function defined by (10)-(11) represents, for $a<0$ :

- (i)-solution to problem (1);

- (ii)-solution to problem (2), if it is (ii)differentiable (*);

- (i)-solution to problem (3), if it is (i)differentiable $(*)$

and, for $a>0$ :

- (ii)-solution to problem (1) (*).

- (i)-solution to problem (2), if it is (i)differentiable (*);

- (ii)-solution to problem (3), if it is (ii)differentiable (*).

Proof: In (10)-(11), if we take $\widehat{\ominus}_{1}=\widehat{\ominus}_{3}=\ominus_{1}=\ominus$ and $\widehat{\ominus}_{2}=\ominus_{2}$, then $\gamma \equiv \psi$ and we obtain function $y_{6}$, so that, in case of existence and differentiability and for $a<0$, we have a (ii)-solution to problem (2) or a (i)-solution to problem (3) (see Theorem 3).

On the other hand, if we take $\widehat{\ominus}_{1}=\widehat{\ominus}_{2}=\ominus_{2}$ and $\widehat{\ominus}_{3}=\ominus_{1}=\ominus$, then $\gamma \equiv \psi$ again and we obtain function $y_{1}$, which, from Theorem 1 is, for $a<0$, the (i)-solution to problem (1).

If we select $\widehat{\ominus}_{1}=\widehat{\ominus}_{2}=\ominus_{1}=\ominus$ and $\widehat{\ominus}_{3}=\ominus_{2}$, then

$$
\begin{aligned}
y(t)= & \cosh (\varphi(t))\left(y_{0} \ominus(-1) \int_{0}^{t} \gamma(s) d s\right) \\
& \ominus-\sinh (\varphi(t))\left(y_{0} \ominus(-1) \int_{0}^{t} \gamma(s) d s\right)
\end{aligned}
$$

and

$$
\begin{aligned}
-\gamma(s) & =-(b(s) \cosh (\varphi(s))-b(s) \sinh (\varphi(s))) \\
& =\phi(s),
\end{aligned}
$$

so that we obtain function $y_{4}$, which is, from Theorem 2 and for $a>0$, the (ii)-solution to problem (1).

Finally, if $\widehat{\ominus}_{1}=\widehat{\ominus}_{3}=\ominus_{2}$ and $\widehat{\ominus}_{2}=\ominus_{1}=\ominus$, then

$$
\begin{aligned}
y(t)= & \cosh (\varphi(t))\left(y_{0}+\int_{0}^{t} \gamma(s) d s\right) \\
& \ominus-\sinh (\varphi(t))\left(y_{0}+\int_{0}^{t} \gamma(s) d s\right),
\end{aligned}
$$


where $\gamma \equiv-\phi$, so that we obtain function $y_{7}$, which is, from Theorem 4 and for $a>0$, a (i)-solution to problem (2) or a (ii)-solution to problem (3).

Moreover, expressions (10)-(11) are also a generalization of (9). This way, (10)-(11) gives a uniform expression for the different solutions obtained.

Theorem 7 The function defined by (10)-(11) generalizes the expression of all the solutions $y_{1}, \ldots, y_{8}$ given in Theorems 1-4.

Proof: This comes from the fact that the function defined by (10)-(11) includes the expression (9) and the proof of Theorems 5-6. Indeed, denote $C(t):=\left(y_{0} \widehat{\ominus}_{1}(-1) \int_{0}^{t} \gamma(s) d s\right)$ (understanding that it is well-defined).

In the case $a>0$, we have $\varphi(t)>0$ and $\cosh (\varphi(t))>\sinh (\varphi(t))>0$, thus, if we consider $\widehat{\ominus}_{2}=\ominus_{2}$ in (10), we get

$$
\begin{aligned}
y(t) & =\cosh (\varphi(t)) C(t)+\sinh (\varphi(t)) C(t) \\
& =(\cosh (\varphi(t))+\sinh (\varphi(t))) C(t)=e^{\varphi(t)} C(t) .
\end{aligned}
$$

Besides, if $\widehat{\ominus}_{3}=\ominus_{1}=\ominus$, since $a>0$,

$$
\begin{aligned}
\gamma(s) & =b(s) \cosh (\varphi(s)) \ominus b(s) \sinh (\varphi(s)) \\
& =b(s)(\cosh (\varphi(s))-\sinh (\varphi(s))) \\
& =b(s) e^{-\varphi(s)},
\end{aligned}
$$

so that we have

$$
y(t)=e^{\varphi(t)}\left(y_{0} \widehat{\ominus}_{1}(-1) \int_{0}^{t} b(s) e^{-\varphi(s)} d s\right)
$$

and it coincides with (9).

On the other hand, if $a<0$, we have $\varphi(t)<0$ and $\cosh (\varphi(t))>-\sinh (\varphi(t))>0$, thus, if we consider $\widehat{\ominus}_{2}=\ominus_{1}=\ominus$ in $(10)$, we obtain

$$
\begin{aligned}
y(t) & =\cosh (\varphi(t)) C(t) \ominus-\sinh (\varphi(t)) C(t) \\
& =(\cosh (\varphi(t))+\sinh (\varphi(t))) C(t)=e^{\varphi(t)} C(t),
\end{aligned}
$$

where we have used that $\lambda u \ominus \mu u=(\lambda-\mu) u$, for $\lambda>\mu>0$. Furthermore, taking $\widehat{\ominus}_{3}=\ominus_{2}$, since $a<0$, we have

$$
\begin{aligned}
\gamma(s) & =b(s) \cosh (\varphi(s))-b(s) \sinh (\varphi(s)) \\
& =b(s) \cosh (\varphi(s))+b(s)(-\sinh (\varphi(s))) \\
& =b(s)(\cosh (\varphi(s))-\sinh (\varphi(s))) \\
& =b(s) e^{-\varphi(s)}
\end{aligned}
$$

and we deduce again the expression (9).

Therefore, as in the proof of Theorem 5 , the choice of $\widehat{\ominus}_{1}$ determines if $y=y_{2}=y_{8}\left(\widehat{\ominus}_{1}=\ominus_{1}=\right.$ $\ominus)$ or $y=y_{3}=y_{5}\left(\widehat{\ominus}_{1}=\ominus_{2}\right)$.

Remark 2 For the case $a \equiv 0$, each of the problems (1)-(3) are reduced to

$$
y^{\prime}(t)=b(t), t \in I, \quad y(0)=y_{0} .
$$

In this case,

$$
y_{1}(t)=y_{3}(t)=y_{5}(t)=y_{7}(t)=y_{0}+\int_{0}^{t} b(s) d s
$$

and

$$
y_{2}(t)=y_{4}(t)=y_{6}(t)=y_{8}(t)=y_{0} \ominus \int_{0}^{t}(-b(s)) d s
$$

(subject to its existence). It is clear that, for $a \equiv 0$,

\begin{tabular}{|c|c|c|}
\hline & $\widehat{\ominus}_{2}=\ominus$ & $\widehat{\ominus}_{2}=\ominus_{2}$ \\
\hline \multirow{2}{*}{$\widehat{\ominus}_{1}=\ominus$} & $\begin{array}{c}\widehat{\ominus}_{3}=\ominus_{2} \\
a<0 \\
\text { Function } y_{2}(*) \\
\text { (ii)-sol. to (1) }\end{array}$ & $\begin{array}{c}\widehat{\ominus}_{3}=\ominus, \\
a<0 \\
\text { Function } y_{6}(*) \\
\text { (ii)-sol. to (2) (d) } \\
\text { (i)-sol. to (3) (d) }\end{array}$ \\
\hline & $\begin{array}{c}\hat{\ominus}_{3}=\ominus_{2} \\
a>0 \\
\text { Function } y_{4}(*) \\
\text { (ii)-sol. to }(1)\end{array}$ & $\begin{array}{c}\widehat{\ominus}_{3}=\ominus, \\
a>0 \\
\text { Function } y_{8}(*) \\
\text { (ii)-sol. to (2) (d) } \\
\text { (i)-sol. to (3) (d) }\end{array}$ \\
\hline \multirow{2}{*}{$\widehat{\ominus}_{1}=\ominus_{2}$} & $\begin{array}{c}\widehat{\ominus}_{3}=\ominus_{2}, \\
a<0 \\
\text { Function } y_{5} \\
\text { (i)-sol. to (2) (d) } \\
\text { (ii)-sol. to (3) (d) }\end{array}$ & $\begin{array}{c}\widehat{\ominus}_{3}=\ominus \\
a<0 \\
\text { Function } y_{1}(*) \\
\text { (i)-sol. to }(1)\end{array}$ \\
\hline & $\begin{array}{c}\widehat{\ominus}_{3}=\ominus_{2}, \\
a>0 \\
\text { Function } y_{7}(*) \\
\text { (i)-sol. to (2) (d) } \\
\text { (ii)-sol. to (3) (d) }\end{array}$ & $\begin{array}{c}\widehat{\ominus}_{3}=\ominus, \\
a>0 \\
\text { Function } y_{3} \\
\text { (i)-sol. to (1) }\end{array}$ \\
\hline
\end{tabular}
(11) gives $\gamma \equiv b$ and (10) is reduced to

$$
y(t)=y_{0} \widehat{\ominus}(-1) \int_{0}^{t} b(s) d s,
$$

while (9) produces the same expression. It is obvious that the previous function coincides with $y_{2 k}$, for $k=1, \ldots, 4$, if $\widehat{\ominus}=\ominus$, and it is exactly $y_{2 k+1}$, for $k=0, \ldots, 3$, if $\widehat{\ominus}=\ominus_{2}$.

To conclude, in Table 1, we summarize the solutions obtained as particular cases of (10)-(11) depending on the choices of the differences $\widehat{\ominus}_{1}, \widehat{\ominus}_{2}$ and $\widehat{\ominus}_{3}$, for $a$ non null. There, we indicate with the symbol $(*)$ the requirement of the existence of the corresponding H-differences and with (d) the requirement of the differentiability of the function involved.

Table 1: Particular solutions obtained from (10)(11) depending on $\widehat{\ominus}_{1}, \widehat{\ominus}_{2}$ and $\widehat{\ominus}_{3}$.

\section{Acknowledgements}

The authors are grateful to the Reviewers for their interesting and valuable comments. This research is partially supported by Fondecyt-Chile through project 1120665 and by Ministerio de Economía y Competitividad, projects MTM2010-15314 and MTM2013-43014-P, co-financed by the European Community fund FEDER. 


\section{References}

[1] B. Bede, T.G. Bhaskar and V. Lakshmikantham, Perspectives of fuzzy initial value problems, Communications in Applied Analysis, 11: 339-358, 2007.

[2] B. Bede and S.G. Gal, Generalizations of the differentiability of fuzzy number valued functions with applications to fuzzy differential equation, Fuzzy Sets and Systems, 151:581-599, 2005.

[3] B. Bede and S.G. Gal, Solutions of fuzzy differential equations based on generalized differentiability, Communications in Mathematical Analysis 9:22-41, 2010.

[4] B. Bede, I.J. Rudas and A.L. Bencsik, First order linear fuzzy differential equations under generalized differentiability, Information Sciences, 177:1648-1662, 2007.

[5] B. Bede and L. Stefanini, Generalized differentiability of fuzzy-valued functions, Fuzzy Sets and Systems 230:119-141, 2013.

[6] T.G. Bhaskar, V. Lakshmikantham and V. Devi, Revisiting fuzzy differential equations, Nonlinear Analysis 58:351-358, 2004.

[7] Y. Chalco-Cano, W.A. Lodwick and B.Bede, Fuzzy differential equations and Zadeh's extension principle, Proceedings of 30th NAFIPS International Conference IEEE, El Paso, 2011.

[8] Y. Chalco-Cano and H. Román-Flores, On new solution of fuzzy differential equations, Chaos, Solitons \& Fractals 38:112-119, 2008.

[9] Y. Chalco-Cano and H. Román-Flores, Comparation between some approaches to solve fuzzy differential equations, Fuzzy Set and Systems 160:1517-1527, 2009.

[10] Y. Chalco-Cano and H. Román-Flores, Some remarks on fuzzy differential equations via differential inclusions, Fuzzy Sets and Systems 230:3-20, 2013.

[11] Y. Chalco-Cano, A. Rufián-Lizana, H. RománFlores and M.D. Jiménez-Gamero, Calculus for interval-valued functions using generalized Hukuhara derivative and applications, Fuzzy Sets and Systems, 219:49-67, 2013.

[12] P. Diamond, Time-dependent differential inclusions, cocycle attractors and fuzzy differential equations, IEEE Trans. Fuzzy Systems 7:734740, 1999

[13] P. Diamond, Stability and periodicity in fuzzy differential equations, IEEE Trans. Fuzzy Systems 8:583-590, 2000.

[14] P. Diamond, Brief note on the variation of constant formula for fuzzy differential equations, Fuzzy Sets and Systems, 129:65-71, 2002.

[15] P. Diamond and P.E. Kloeden, Metric Spaces of Fuzzy Sets: theory and applications, World Scientific, Singapore, 1994.

[16] D. Dubois and H. Prade, Towards fuzzy differential calculus Part III: Differentiation, Fuzzy Sets and Systems 8:225-233, 1982.
[17] E. Hüllermeier, An approach to modeling and simulation of uncertain dynamical systems, International Journal Uncertainty, Fuzziness Knowledge-Based Systems 5:117-137, 1997.

[18] E. Hüllermeier, Numerical methods for fuzzy initial value problems, International Journal Uncertainty, Fuzziness Knowledge-Based Systems 7:1-23, 1999.

[19] O. Kaleva, Fuzzy differential equations, Fuzzy Sets and Systems, 24:301-317, 1987.

[20] O. Kaleva, The Cauchy problem for fuzzy differential equations, Fuzzy Sets and Systems, 35:389-396, 1990.

[21] O. Kaleva, A note on fuzzy differential equations, Nonlinear Analysis, 64:895-900, 2006.

[22] A. Khastan, J.J. Nieto and R. RodríguezLópez, Variation of constant formula for first order fuzzy differential equations, Fuzzy Sets and Systems, 177:20-33, 2011.

[23] A. Khastan, J.J. Nieto and R. RodríguezLópez, Fuzzy delay differential equations under generalized differentiability, Information Sciences, 275:145-167, 2014.

[24] A. Khastan and R. Rodríguez-López, On the solutions to first order linear fuzzy differential equations, preprint.

[25] V. Lakshmikantham and R.N. Mohapatra, Theory of Fuzzy Differential Equations and Inlusions, Taylor \& Francis, New York, 2003.

[26] V. Lupulescu, On a class of fuzzy functional differential equations, Fuzzy Sets and Systems 160:1547-1562, 2009.

[27] M. Misukoshi, L.C. Barros, Y. Chalco-Cano, H. Román-Flores and R.C. Bassanezi, Fuzzy differential equations and the extension principle, Information Sciences 177: 3627-3635, 2007.

[28] J.J. Nieto, A. Khastan and K. Ivaz, Numerical solution of fuzzy differential equations under generalized differentiability, Nonlinear Analysis: Hybrid Systems, 3:700-707, 2009.

[29] J.J. Nieto, R. Rodríguez-López and D. Franco, Linear first order fuzzy differential equations, Int. J. Uncertainty Fuzziness Knowledge-Based Syst, 14:687-709, 2006.

[30] J.J. Nieto, R. Rodríguez-López and D.N. Georgiou, Fuzzy differential systems under generalized metric spaces approach, Dynamic Systems Appl., 17:1-24, 2008.

[31] M.L. Puri and D.A. Ralescu, Differentials of fuzzy functions, Journal of Mathematical Analysis and Applications, 91:552-558, 1983.

[32] R. Rodríguez-López, On the existence of solutions to periodic boundary value problems for fuzzy linear differential equations, Fuzzy Sets and Systems, 219:1-26, 2013.

[33] H. Román-Flores, L.C. Barros and R.C.Bassanezi, A note on Zadeh's extension, Fuzzy Sets and Systems 117:327-331, 2001.

[34] H. Román-Flores and M.A. Rojas-Medar, Em- 
bedding of level-continuous fuzzy sets on Banach spaces, Information Sciences 144:227-247, 2002.

[35] T. Rzezuchowski, J. Wasowski and J. Wimagesowski, Differential equations with fuzzy parameters via differential inclusions, Journal of Mathematical Analysis and Applications 255:177-194, 2001.

[36] S. Seikkala, On the fuzzy initial value problem, Fuzzy Sets and Systems 24:319-330, 1987.

[37] L. Stefanini, A generalization of Hukuhara difference and division for interval and fuzzy arithmetic, Fuzzy Sets and Systems, 161:1564-1584, 2010.

[38] L. Stefanini and B. Bede, Generalized Hukuhara differentiability of interval-valued functions and interval differential equations. Nonlinear Analysis: TMA, 71:1311-1328, 2009.

[39] L. Stefanini, L. Sorini and M.L. Guerra, Parametric representation of fuzzy numbers and application to fuzzy calculus, Fuzzy Sets and Systems, 157:2423-2455, 2006. 